\title{
Do they all fail? A comparative analysis of performance-related pay systems in local governments
}

\author{
Isabella Proeller, Anne-Kathrin Wenzel, Dominik Vogel, Riccardo Mussari, Donatella Casale, \\ Emil Turc, Marcel Guenoun
}

This is a post-print of the following book chapter: Proeller, I./Wenzel, A.-K./Vogel, D./Mussari,

R./Casale, D./Turc, E./Guenoun, M. (2016). Do they all fail? A comparative analysis of performance-related pay systems in local governments. 139-152. In: Bouckaert, G./Kuhlmann, S. (Hrsg.): Local Public Sector Reforms in Times of Crisis. Manchester: Palgrave Macmillan.

\begin{abstract}
The introduction of performance-related pay (PRP) in the public sector has been one of the main trends in public management reform in the last two decades. However, it seems that PRP regimes have been loosened or even backed off the reform agenda, often with the notion that they were not used as planned, failed to deliver, and ultimately were stalled as being an incompatible control instrument to the existing administrative culture. Focusing on the local government level in Germany, France and Italy, the authors explore the question why PRP systems have failed to manifest a core position in the performance oriented reform agendas. Diffusion and implementation practice in the three countries shows significant differences and leads to relevant heterogeneity and variance of implementation of PRP.
\end{abstract}

\section{Introduction}

Performance related Pay (PRP) regimes have been promoted as instruments to boost efficiency, motivation and performance orientation of the public sector and its employees. However, implementation experiences revealed that PRP is not a quick and easy win instrument, and expected results of PRP often could not be realized. Previous evaluations have identified severe weaknesses in PRP schemes in the public sector (Perry 2009). Not only that expected effects like motivation crowding-in were regularly not realized, looking at the reform discourse and development in some European countries it seems that PRP regimes have been loosened or even backed off the reform agenda, often with the notion that PRP systems were not used as planned, failed to deliver, and ultimately were stalled as being an incompatible control instrument to the 
existing administrative culture. The local government level in Germany, France and Italy are examples for such developments with rather reluctant accounts regarding the successful implementation of PRP systems. These three national local government levels will serve as comparative cases to explore the question why PRP systems have failed to manifest a core position in the performance oriented reform agendas. The research interest of this chapter focuses on finding out what can explain that a once clearly positioned and regulated reform policy like PRP is taken off the reform agenda rather quickly. From a rational perspective, the abandonment or repositioning of a reform could be explained as functionalist, e.g. the reform has not delivered what is was designed for and was therefore dismissed due to lacking problem solving capacities. From a sociological neo-institutionalist perspective, it could be argued that also the abandonment of a certain reform trajectory can follow a logic of appropriateness (March and Olsen 1989). As a process of mimetic isomorphism, to not further push for this particular reform policy would then become the newly emerged social norm. By comparatively analyzing the three case studies against those theoretical perspectives, we aim to better identify potential influencing factors and mechanism. In the case of France we observe a case that has degraded its PRP reform, while Italy and Germany have also experienced sobering results with PRP, but it still remains a part of the reform package. Methodologically, we therefore have two similar and a dissimilar case with respect to our object of analysis, the continuity of PRP as reform trajectory. In the following, we will shortly describe the origins, designs and current accounts of implementation experiences in the three countries, before we synthesis the comparison with regard to our research interest and further research.

\begin{tabular}{|l|l|l|l|}
\hline $\begin{array}{l}\text { Characteristics of the civil } \\
\text { service }\end{array}$ & GERMANY & ITALY & FRANCE \\
\hline $\begin{array}{l}\text { Number of Public } \\
\text { Employees }\end{array}$ & $4.6 \mathrm{Mio}$ & 3.4 Mio (2010) & 5.4 Mio (2011) \\
\hline $\begin{array}{l}\text { Number of local employees } \\
\text { Länder) }\end{array}$ & $\begin{array}{l}3.18 \text { Mio (incl. } \\
\text { Proportion of personnel at } \\
\text { the local level (as \% of tot. } \\
\text { public employees) }\end{array}$ & 0.57 Mio & 1.81 Mio. (2011) \\
\hline $\begin{array}{l}\text { Distribution per layer } \\
\text { Länder 60\% }\end{array}$ & $\begin{array}{l}\text { Municipalities } \\
76 \%, \\
\text { Punicipalities 27\% }\end{array}$ & $\begin{array}{l}\text { Municipalities } 63 \% \\
\text { Intercommunal } \\
\text { organizations: } 13 \% \\
\text { Provinces : } 20 \%\end{array}$ \\
\hline
\end{tabular}




\section{PRP in Germany}

\subsection{Origin}

Only in 2003, a commission on the reform of the public sector recommended the introduction of an effective reform of the reimbursement system including PRP (Regierungskommission 2003). The suggestions finally lead to the reform of the "Collective Agreement for the Public Service" (TVöD and TV-L). This constitutes the duty for public administrations at all levels to introduce PRP starting in 2007. In the following, we will concentrate on the description of PRP for public employees as the regulations for civil servants are completely different and only concern a minority of the people employed at the local level (a share of 13.3 per cent are civil servants).

With the introduction of PRP, the motivation, self-responsibility and leadership skills of employees working in the public service should increase. Initially, PRP was launched with a budget of one per cent of the basic pay of all employees of the respective organization in the previous year and has already risen up to two per cent. It has been planned to increase the amount up to eight per cent. It is paid on top of the regular salary and there is no chance to lower the salary due to bad performance. All employees of an organization are eligible to get PRP and no official quota is applied.

\subsection{Design}

German public administrations enjoy a lot of discretion to design the concept of PRP. The collective agreement for the public sector ( $\S 18 \mathrm{TV}$ öD) merely regulates the basic framework of the performance payment; more specific regulations have to be decided in mutual agreements ("Dienstvereinbarung") by the bargaining parties (employer and staff council) of the respective organization. In the mutual agreements, the employer and the staff council especially have to agree on the type of performance appraisals, the distribution of PRP and the performance appraisal methods.

There are three types of PRP: The most commonly used is the performance bonus, which is usually paid once a year. Besides, organizations can pay bonuses based on the fulfilment of economic goals by single employees or a team and incentive bonus payments, which are both rarely used.

Regarding the allocation of the budget, the organizations can decide whether they divide the organizational PRP budget into sub-budgets or use one budget for all employees of the organization. In the case of a division by departments, there is an individual budget for every department and only the performance ratings of every department's employees are compared and transformed into the individual amounts of PRP. It is often argued that this is fairer as it reduces the chance that there are different appraisers using different performance criteria for the performance appraisals.

Two methods of performance appraisal can be applied: agreement on goals and systematic performance appraisals. The agreement on goals is characterized as a voluntary contract between a single employee or a team and the supervisor on three to five targets. By using systematic performance appraisals, supervisors have to use objective and measurable criteria for 
the performance assessment. It is up to the mutual agreement whether to allow only one method of performance appraisal or both methods.

Different studies provide evidence that employees perceive agreements on goals as notably fairer, more transparent and participative compared to systematic performance appraisals (Meier 2013; Erez, Earley, and Hulin 1985). It remained unclear for a long time whether it makes a difference if the goals are agreed between the employer and a single employee or a team. The results of a survey by Meier (2013), confirmed that team agreements on goals lead to less envy between employees than other appraisal methods. Nevertheless, individual agreements on goals show a strong influence on transparency and fairness of the performance appraisal as well as on participation within the goal setting process than team agreements (ibid).

\subsection{Implementation and criticalities}

Despite several years of the application of PRP in the German public administrations including LGOs, there are few evaluation studies that demonstrate what effect performance pay actually has and how the employees perceive the different appraisal methods (Meier 2013; Schmidt, Trittel, and Müller 2011; Schmidt and Müller 2013).

In 2013, Meier surveyed 21 German county councils and cities with county status in order to analyze whether the introduction of PRP in the public service resulted in crowding effects of intrinsic motivation and public service motivation (PSM). The performance appraisal schemes' design turned out to be the by far most influential factor regarding the perception of PRP. Particularly, the perceived fairness and transparency of performance appraisal systems are influential.

In the international context it has been frequently criticized that there is a tendency to "reward" a very high proportion of employees with the best possible rating within the performance appraisal process (Landy and Farr 1983; Perry, Petrakis, and Miller 1989). The limited data suggest that more than 90 per cent of employees receive at least some performance pay (Meier 2013). The percentage of those who get the best performance appraisal is very high and varies from 56 per cent (Meier 2013) to 59 per cent (Schmidt and Müller 2013). The study of Meier (2013) has also shown that the choice of the performance appraisal method influences the chance of getting the highest rating: agreements on goals offer a significantly higher chance to get the best performance rating while it seems to be very hard for those employees who are rated with systematic performance appraisals. This finding is especially relevant for those organizations which implemented both appraisal methods.

The low amount of PRP, is often seen as a reason for the employees' dissatisfaction with it. This might explain the mildness of the appraisers as they might see (too) good performance appraisals as a potential for motivation while more realistic performance appraisals might demotivate the employees. But in the end, this way totally defeats the principle of performance pay.

The differentiation between public employees and civil servants also leads to problems, although both groups work together in the same teams, there are completely different regulations concerning PRP. The regulations of $\S 18 \mathrm{TV}$ öD only apply for public employees. 
Civil servants are also eligible to get PRP but based on other regulations that also differ between the federal states (Weber 2013).

In the end, PRP has caused a lot of discussions and problems in the German public sector. In 2009 , it has already been abolished on the federal level. Since 2014, there is no duty to distribute PRP at the state level. The trade union essentially argues that it does not fulfil its purpose and leads to discord and enviousness between employees (ver.di 2011).

\section{PRP in France}

\subsection{Origin}

Performance bonuses in the French civil service are a relatively new development, gaining strength and visibility during the late 2000s (Carrez, 2007). The PFR (bonus for functions and results - Prime de Fonctions et de Résultats) was rapidly translated into law (2008). Along with Law 2010-751, this ends the decades-long ban on personalized variable pay in the French civil service.

From an organizational standpoint, the mission of PFR was to replace the existing approx. 1.800 bonuses across the national and local government administration, and secure a more equitable treatment for agents with comparable jobs across public administrations (Silicani 2008).

Breaking-up with the general culture of uniformity and bonuses based on "impersonal" criteria, the PFR was also seen as a mean to expand managerial leeway, giving direct supervisors the possibility to incentivize subordinates through individual goal-setting, evaluation, and bonuses. Eventually, and in a context of austerity, the PFR was to reconcile and improve the management of salary budgets, wage raises, and the recognition of professional value and work performances. Concurrently, the government introduced in 2010 the possibility of collective incentive schemes. However, the interest for this PRP tool was quickly stalled, with trade unions perceiving it as a disguised mechanism for personnel reduction and financial cutbacks (2011).

\subsection{Design}

According to the law, the PFR includes two parts: the functional bonus PF (Prime de Fonctions) and the performance-related bonus PR (Prime de résultats). The assessment of each follows specific calculations, but they are jointly paid on top of the yearly base salary as determined by the career index and national grids. First, the functional part is meant to acknowledge the professional trajectory of the agent. While the PF bonus may have appeared as a recognition of professional worth, it is more closely aligned to the OECD's (2005) vision of allowances for certain posts and working conditions. Specifically, the PF depends on new "objective" categorizations of jobs produced by the ministries and LGOs and is unconnected to the personal characteristics of the agent.

Secondly, the Prime de Résultats (PR) part is formally connected to the annual assessment interview of each civil servant. It integrates multiple criteria such as: commitment to serve, the achievement of annual objectives set by the supervisor, personal involvement, interpersonal skills, and the acquisition of other competencies and skills required on the job. This explains the 
de facto categorization of the PR part as a PRP tool, although the merit bonus (professional worth and competence) and pay for results (goal-related) are not separated and follow a single procedure of assessment and attribution.

As for amounts, the PFR may make a significant difference. For instance, middle managers of the national civil service could reach in 2011 a PF bonus of 15,600 $€$ and a PR bonus of 10,200 $€$ per year. A concern for equity appears as the superior margins of the PFR's parts are bound by national limits for each category of civil servants. As for volunteering LGOs, their councils must validate and enact all the limits and modalities of their PFR systems.

\subsection{Implementation and criticalities}

While the PFR has been widely promoted as a support for civil servant motivation, its design appears as a barrier to achieving this goal. The beginnings of PRP in the local civil service coincide with those of the national services (Law 751/2010, Decree 1705/2010). But the pace of reforms in LGOs was relented by the constitutional principle of freedom of administration. The extension of PFR was seen as an optional process, depending on the decisions of the LGOs' councils to try it out or pursue with the previous system of bonuses and allowances.

To analyze the level of implementation of PRP tools and their effects, original qualitative interview data was gathere ${ }^{1}$ and was completed by second hand data and a literature review. So far, the application of PRP tools calls for the following comments: Their implementation and diffusion is extremely limited, almost anecdotal. The ensuing budgetary inflation is widely acknowledged by the profession as an essential reason why PFR was not diffused more widely across the LGOs in the context of economic crisis. Second, local adaptations of the design of PFR limit drastically the part connected to the employee's results, hence its kinship to PRP systems. The $P F$ part, which depends on the position occupied by the agent, ended up dominating the $P R$ part (60:40). Further, within the context of LGO administrative culture the implementation of PFR came at the cost of budget inflation and significant distortions of its initial goals. The PFR was based on a uniform method, in which widespread communication on LGO-wide criteria and procedures was appreciated by both administrators and employees. Yet, as experiments went on, the decision-makers were unsettled. Inflationary effects of PFR on total payroll contributed to reduce the LGO's financial leeway. Lastly, the local adaptations of PFR were swift to reach their limits, leading to demands for a renewal or abandonment of the system. Their resource-intensive implementation and inflationary perception were incompatible with the decreasing finances of French LGOs.

Eventually, the vote into law of a new bonus system (IFSE, 20/05/2014) made optional the results-based bonus for the whole civil service. This confirms the profession's preference for a simplification tool, rather than a performance-based HR instrument.

\footnotetext{
${ }^{1}$ In summer 2014 five interviews with HRM officers in French LGOs, involved in professionals associations and some of them having implemented PRP were conducted.
} 


\section{PRP in Italy}

\subsection{Origin}

PRP system has been recently reformed following a typical top-down approach through the introduction of the decree law n. 150/2009 that aimed at strengthening the already existing principles introduced by previous reforms during the past years. In fact, the 1990s intense public management reform in Italy mainly concerned public employment's institutional design, career progressions and remuneration systems (Ongaro 2009; Mele 2010; Capano and Gualmini 2006) and special units devoted to the performance management "Nuclei di Valutazione" were introduced in every local council (decree 142/1990). Subsequently, a comprehensive reform of the civil service introduced a first kit of performance instruments in LGOs (decree 29/1993). Notwithstanding these efforts, a proper performance-related pay system for public managers was not yet introduced (Mussari and Ruggiero 2010).

\begin{tabular}{lcccc}
\hline & Ministers & Regions & Provinces \\
\hline Number of Managers & $4.028(21,3 \%)$ & $3.265(37,4 \%)$ & $1.782(9,5 \%)$ & Municipalities \\
Managers/100 employees & 2,1 & 7,7 & 3.2 & $5.638(31,8 \%)$ \\
Average Age & 54,2 & 53,8 & 51,4 & 2,1 \\
Average length of service & 23,7 & 23,6 & 17.7 & 50,7 \\
Average gross annual pay (euro) & 87.248 & 86.199 & 80.592 & 18 \\
\% of pay for performance & $5 \%$ & $9,7 \%$ & $8,5 \%$ & 73.866 \\
\hline
\end{tabular}

Table 2 Reward structure and managers in Italian public administration (Cristofoli, D., Turrini, A., Vallotti, G., 2007)

\subsection{Design}

The above mentioned reform of 2009 (decree 150/2009) introduced a comprehensive and sophisticated system of PRP aimed at the evaluation and measurement of individual and organizational performance in Italian public sector. The main principles and promoted values are the obligation to measure and evaluate performance, along with the enhancement of merit through the provision of bonuses linked to individual and organizational performance.

The decree introduced a process ("performance cycle") organized around a three-year planning document (performance plan) indicating the strategic and operational objectives along with the indicators apt to measure organizational and individual performance. Besides it, each administration must issue a performance report that function as a feedback on achievement of both strategic and operational objectives by providing a decay of the strategic objectives included in the performance plan into annual objectives.

The performance of all employees of local administrations is evaluated. The evaluation of individual performance is made in accordance with the executive management plan ("piano esecutivo di gestione") and the formal attribution of individual objectives in each LGO. In particular every organization must adopt the executive management plan ("piano esecutivo di gestione") and formally attribute individual objectives. 
The bonuses available are distributed according to the results of the formal evaluation of individual performances and are calculated implementing specific algorisms, which are defined in accordance with collective integrative decentralized bargaining ("contrattazione collettiva decentrata integrativa"). According to the legislation three types of bonuses are designed to promote performance orientation: 1) bonuses based on performance, which are the annual excellence bonuses for managerial and non-managerial staff and efficiency bonuses that consist in the allocation of a quota of 30 per cent of resources deriving by contingent savings due to reorganization or innovation to performance appraisal of the public personnel directly involved in those operations. 2) bonuses based on special success, which are annual innovation bonuses for the best projects in terms of improvement, change regarding internal processes, organizational performance, and/or the quality of a public service; and 3) incentive bonus payments which consist in economic and career progressions. In particular, the bonuses for individual productivity and/or collective are defined according to article 17 CCNL 1.4.1999 and article 37 CCNL 22.1.2004 plus article 26 and following articles of CCNL 23.12.1999 (« comparto dirigenti $»)$. The resources devoted to the bonuses are defined in accordance to the articles 31 CCNL 22.1.2004 and 26 CCNL 23.12.1999.

\subsection{Implementation and criticalities}

A recent survey on 169 local administrations conducted between 2010-2011 by Di Mascio and Natalini (2013) found that 54.8 per cent of the observed LGOs, do not effectively use performance-related pay. In addition, since the municipalities are required to publish PRPrelated data on their websites, the above-mentioned survey showed that only 23 per cent of the administrations proved to be compliant with this requirement.

In general, performance management suffers because of difficult application due to the complexity of the structures and the nature of activities of the public sector. The context of wide-spreading emphasis on performance measurement despite public sector's loss of competitiveness and productivity and fiscal stress (Italian Court of Auditors 2012, 50; law 94/2012; decree 07/05/2012) undermines the capability of LGOs to distribute resources in accordance to the above-mentioned bonuses outlined by the legislation. Moreover, the differences in the implementation in Italian LGOs (Borgonovi 2005; Ruffini et al. 2011; Spano and Asquer 2011) also show the problematical adaptation to the newly introduced performance schemes in different organizations, which demonstrate resistance to change and collision against consolidated bureaucratic cultures.

\section{Conclusion}

Diffusion and implementation practice in the three countries shows significant differences and leads to relevant heterogeneity and variance of implementation of PRP. While PRP is implemented in most of Italian LGOs and the majority of German LGOs, diffusion of PRP is very limited in France. A main reason involves the different legal requirements associated with the implementation of PRP. Italian LGOs are expected by law to use PRP and German LGOs at least have to spend the budget dedicated to PRP. In contrast, French LGOs are allowed to decide on their own if they use PRP or not and if they are willing and capable to allocate resources for 
it. However, there is a further gap of this formal implementation on the talk and decision level (Brunsson 1989), and the action level of implementation in each LGO. So, for example, the survey of Meier (2013) has shown that up to 58\% of LGOs per federal state ignore and pervert the PRP system on the action level by simply assigning everybody the same PRP bonus.

Our main research interest was on the continuity of PRP as reform trajectory. Italy - and to date also Germany on the local level - is continuing its current systems and currently shows no indication to lessen or loosen its controls and regulations for PRP, while in France we observe a de facto withdrawal from the prime de resultat, e.g. the performance oriented part of the bonus system. Evaluating the developments through the theoretical lenses it seems that the functionalist argument is only of limited explanatory power. The sketchy and limited evaluative accounts that exist to date on the effects of the PRP reforms rather point to the conclusion that the expected improvements for motivation and efficiency gains have stayed behind expectations in all national contexts. Even though there are - as for example for the German case - also examples and constellations where motivation has been systematically increased, the overall and total effects are sobering. Taking into account insights of recent international research on PRP motivational effects, to boost the motivational effect of PRP it would be important to stress the supporting character of the PRP procedures (Jacobsen and Andersen 2014, Andersen and Pallesen 2008, Meier 2013). But, reform adjustments and efforts to foster intended effects were not described as core intentions in the case studies which might be interpreted as a lacking interest to make the systems work beyond just having them. Turning to the logic of appropriateness, the different coping and dismissal strategies that were observed in France can be explained and interpreted by this perspective, as well as the continuing compliance approach that describes the Italian but also the German practice. While in the beginning of the reforms the logic of appropriateness seemed to be much more internationally coined and influenced, also leading to an international reform trajectory of PRP, there is more national variance with regard to what is considered as appropriate in the course of the reform. As our case studies illustrated, there is variance between the national LGOs of what is considered as accepted, legitimate, appropriate, expected implementation and development of the reform. Hereto the different degree of institutional and systematic linkage of the PRP system to other, comprehensive control systems might be a relevant explanatory factor. Since, in Italy we observe a highly interlinked PRP system which is embedded and systematically linked to a more comprehensive performance oriented administrative control system. In France and in Germany, PRP systems were rather operated on their own with much more discretionary links to other, not necessarily performance oriented control systems. Obviously this first, general comparative analysis of PRP systems in Italian, French and German LGOs is of limited validity and reliability. However, the theoretically driven analysis points us to an area worth of further research beyond the analysis of direct and indirect effects of PRP systems on motivation. So, as this chapter sees a potential reason in different developments of PRP system in their systematic links to other control systems, future research might take up this strand and further explore the effects of an integration of PRP systems in administrative control systems to, ultimately, further clarify the question if systems were PRP is linked and integrated in a wider performance oriented control system actually work better in terms of motivational and efficiency gains. 


\section{References}

Andersen, Lotte and Pallesen, Thomas. 2008. Not just for the money? How financial incentives affect the number of publications at Danish Research institutions. In: IPMJ 11: 28-47

Borgonovi, Elio. 2005. Principi e sistemi aziendali per le amministrazioni pubbliche. 5. ed. I manuali / [EGEA] 25. Milano: EGEA.

Brunsson, Nils. 1989. The organization of hypocrisy. Talk, decisions and actions in organizations. Chichester: Wiley.

Capano, Giliberto, and Elisabetta Gualmini. 2006. "La pubblica amministrazione in Italia (Ed.).".

Carrez, G. 2007. "Rapport fait au nom de la Commission des finances, de l'économie générale et du plan sur le Projet de loi de finances pour 2008 (n 189).”.

Cristofoli, D., Turrini, A., Vallotti, G. (2007). Da burocrati a manager: Una riforma a metà. Primo Rapporto sulla Dirigenza Pubblica Italiana. Milano: EGEA.

Di Mascio, F., and A. Natalini. 2013. "Context and Mechanisms in Administrative Reform Processes: Performance Management Within Italian Local Government.” 16 (1): 141-66.

Erez, Miriam, P. C. Earley, and Charles L. Hulin. 1985. "The Impact of Participation on Goal Acceptance and Performance: A Two-Step Model." Academy of Management journal 28 (1): 50-66.

Italian Court of Auditors. 2012. "Corte dei Conti (2012) Relazione 2012 sul costo del lavoro pubblico.".

Jacobsen, Christian and Andesen, Lotte. 2014. Performance Management in the Public Sector: Does it Decrease or Increase Innovation and Performance? in: IJPA 37:1011-1023

Landy, Frank J., and James L. Farr. 1983. The measurement of work performance: Methods, theory, and applications. New York: Academic Press.

March, James G., and Johan P. Olsen. 1989. Rediscovering Institutions. The Organizational Basis of Politics. The Free Press, New York.

Meier, Anne-Kathrin. 2013. Determining factors of the perception of performance-pay systems. An analysis of a survey in German local administrations: Paper presented at the EGPA Annual Conference, Edinburgh (UK), 11-13 September 2013.

Mele, Valentina. 2010. "Innovation Policy in Italy (1993-2002): Understanding the Invention and Persistence of a Public Management Reform." Governance 23 (2): 251-76.

Mussari, Riccardo, and Pasquale Ruggiero. 2010. "Public Managers' Performance Evaluation Systems and Public Value Creation: Behavioral and Economic Aspects." International Journal of Public Administration 33 (11): 541-48.

Ongaro, Edoardo. 2009. Public management reform and modernization: Trajectories of administrative change in Italy, France, Greece, Portugal and Spain. Cheltenham, UK, Northampton, MA: Edward Elgar.

O. E.C. D. 2005. Performance-Related Pay Policies for Government Employees. OECD, Paris.

Perry, J.L., B.A. Petrakis, and T.K. Miller. 1989. "Federal merit pay, round II: An analysis of the performance management and recognition system." Public Administration Review 49 (1): $29-37$. 
Perry, James L., Trent A. Engbers, and So Y. Jun. 2009. "Back to the Future? Performance-Related Pay, Empirical Research, and the Perils of Persistence." Public Administration Review 69 (1): 39-51.

Regierungskommission, N. R. 2003. Zukunft des öffentlichen Dienstes-Öffentlicher Dienst der Zukunft. Anlageband zum Bericht der Regierungskommission NRW. Düsseldorf: Innenministerium des Landes NRW.

Ruffini, R., L. Bottone, and R. Giovannetti. 2011. Il performance management negli Enti Locali. Logiche e metodologie in applicazione della Riforma Brunetta. Rimini: Maggioli Editore.

Schmidt, Werner, and Andrea Müller. 2013. Leistungsorientierte Bezahlung in den Kommunen: Befunde einer bundesweiten Untersuchung. Berlin: Ed. Sigma.

Schmidt, Werner, Nele Trittel, and Andrea Müller. 2011. "Performance-related pay in German public services: The example of local authorities in North Rhine-Westphalia." Employee Relations 33 (2): 140-58.

Silicani, J.-L. 2008. "Livre blanc sur l'avenir de la fonction publique: faire des services publics et de la fonction publique des atouts pour la France." La documentation Française, Paris.

Spano, Alessandro, and Alberto Asquer. 2011. "Performance Review and Assessment of Public Managers: Some Evidence from Local Governments in Italy." International Journal of Public Administration 34 (7): 461-72.

ver.di. 2011. "Antrag E 150 (Abschaffung des $\S 18$ TVöD) an den Bundeskongress 2011.” Accessed June 11, 2013. http://bundeskongress2011.verdi.de/antraege/antrag.html?cat=E\&sort=150\&aid=9367.

Weber, Klaus. 2013. "Leistungsbezahlung im Beamtenbereich. Überblick über dienstrechtliche Gegebenheiten." Der Personalrat (3): 101-05. 